\title{
Age Difference in the Response to Synthetic Luteinizing Hormone-Releasing Hormone (LHRH) in Androgenized Rats with Special Reference to the Dose of Testosterone Propionate for Androgenization
}

\author{
Tомоко FUJII ${ }^{1 *}$, Junzo $\mathrm{KATO}^{2}$ and KATsumi WAKABAYASHI ${ }^{3}$ \\ ${ }^{1}$ Department of Pharmacology, Tokyo Women's Medical College, \\ Tokyo 162, '2Department of Obstetrics and Gynecology, Teikyo \\ University School of Medicine, Tokyo 173 and ${ }^{3}$ Institute of \\ Endocrinology, Gunma University, Maebashi 371, Japan
}

\begin{abstract}
Synopsis
Five-day-old female rats were androgenized with 1,000 or $100 \mu \mathrm{g}$ testosterone propionate and were examined regarding the response to $\mathrm{LHRH}$ at 4, 7 and 12 weeks of age by measuring peripheral LH concentrations. The order of magnitude in LH release was $7>4>12$ weeks old, whereas in normal rats, $4>12>7$ weeks old. LH release in 4- and 7-week-old rats was higher than that in normal controls at the respective age, but was much lower than that in normal controls 12 weeks old. The LH release by Des-Gly ${ }^{10}$-(D-Ala ${ }^{6}$-LHRH-ethylamide (TAP127) was greater than that by natural LHRH both in normal and androgenized rats at 7 or 12 weeks old.

The results indicate that the pituitary gland in androgenized rats responds to LHRH to a much larger extent during the premature period and its responsiveness declines during the course of maturation. A marked hypersensitivity was observed in 7-week-old rats androgenized with $100 \mu \mathrm{g}$ testosterone propionate. The process of androgenization may include the induction of alterations in the sensitivity of the pituitary to LHRH and probably in the LH synthesizing ability of the pituitary.
\end{abstract}

Androgen-sterilized rats are characteristic in possessing anovulation, persistent estrus and polycystic ovaries. Lack of cyclic discharge of LH has been suggested (Kurcz et al., 1969; Flérkó et al., 1969), though ovulation can be induced by administration of synthetic LHRH (Cortes et al., 1971) or gonadotropins (Borvendég et al., 1972; Ying, 1973). Fujii et al. (1973) have reported that thyroidectomy in adult androgenized rats restored an irregular cyclicity for a period of a few months associating with occasional increases in the serum LH level on the late afternoon of

\footnotetext{
Received October 28, 1977.

* Present Address: Department of Pharmacology, Teikyo.University Schood of Medicine, Tokyo 173.
}

proestrus, whereas thyroidectomy in 4-weekold androgenized rats failed to restore any cyclicity afterwards. These results suggest an age difference in the responsiveness of the ovulation-controlling center or of the pituitary gland to the deprivation of thyroid hormones in androgenized rats. This finding may also suggest a possible existence of age difference in the response to gonadotropin-releasing hormone in androgenized rats. In normal rats, a greater response of the anterior pituitary to exogenous LHRH has been demonstrated in younger animals (Debéljuk et al., 1972).

The time of the onset of persistent estrus in androgenized female rats has been shown to be dependent upon the dose of testosterone propionate and the age of 
animals at the time of hormone injection (for review see Barraclough, 1966). The delayed onset of persistent estrus with a low dose of testosterone propionate suggests that the different process of the functional alterations may take place in the neural center that regulates ovulation. This may also be reflected in the sensitivity of the pituitary to endogenous or exogenous LHRH.

The present experiments, therefore, were undertaken to investigate the response to synthetic LHRH at different, ages of rats androgenized with high or low doses of testosterone propionate.

\section{Materials and Methods}

Wistar-Imamichi strain female rats were androgenized by a subcutaneous injection of $100 \mu \mathrm{g}$ (TP $100 \mathrm{~A}$ ) or $1000 \mu \mathrm{g}$ (TP1000A) testosterone propionate dissolved in $0.05 \mathrm{~m} l$ of olive oil on day 5 of life. The normal control female rats at 5 days of age were injected with olive oil alone. They were housed in an air-conditioned room with a lighting schedule of 14-hr light (6:00 a.m. $-8 \div 00$ p.m.) and 10-hr darkness, and fed on Oriental Rat Chow (Oriental Yeast Co., Ltd.) and water ad libitum. The normal control rats at 7 weeks or 12 weeks of age were used all at their estrus. Both androgenized and sham-treated rats at 4, 7 and 12 weeks old were injected iv with synthetic LHRH $(5 \mu \mathrm{g} / \mathrm{kg}$, Mochida Pharmaceutical Co.), and blood samples were collected by decapitation. Des-Gly ${ }^{10}$ )-D-D-Ala ${ }^{6}$ )-LHRH-ethylamide (TAP127, Takeda Pharmaceutical Co.) dissolved in $0.9 \%$ saline, at a dose of $0.5 \mu \mathrm{g} / \mathrm{kg}$, was injected iv into 7- and 12-week-old normal and androgenized rats, and blood samples were collected 30 and $60 \mathrm{~min}$ after the injection. The sera separated were kept frozen until the assay for LH. The ovary and anterior pituitary were dissected out and weighed. The pituitaries were homogenized in $1 \mathrm{ml}$ saline and the supernatant fluid was stored frozen until assayed. LH in the serum and pituitary were determined by standard double antibody radioimmunoassay (Wakabayashi et al., 1975) with NIAMDD radioimmunoassay kits supplied by the Rat Pituitary Hormone Program. The results were expressed in terms of ng of NIH-LH-S1.

\section{Results}

\section{Organ Weights}

The relative weights of the anterior pituitary of TP100A rats at 7 weeks of age and of TP1000A rats at 4 and 7 weeks of age did not show any significant difference as compared with those of normal

Table 2. LH concentrations in the anterior pituitary of normal, TP $100 \mathrm{~A}$ and TP1000A rats at different ages.

\begin{tabular}{clcc}
\hline $\begin{array}{c}\text { Age } \\
\text { (weeks) }\end{array}$ & Groups & $\begin{array}{c}\text { No. of } \\
\text { rats }\end{array}$ & $\begin{array}{c}\text { LH concentration } \\
\mu \text { g NIH-LH-S1/mg } \\
\text { ant. pituitary }\end{array}$ \\
\hline 4 & Normal & 5 & $1.32 \pm 0.12^{\mathrm{a}}$ \\
& TP1000A & 5 & $1.00 \pm 0.16$ \\
7 & Normal & 4 & $0.33 \pm 0.03$ \\
& TP100A & 4 & $0.32 \pm 0.02$ \\
12 & TP1000A & 4 & $0.26 \pm 0.07$ \\
& Normal & 5 & $0.42 \pm 0.04$ \\
& TP100A & 8 & $0.33 \pm 0.03^{*}$ \\
& TP1000A & 8 & $0.22 \pm 0.03^{* *}$ \\
\hline
\end{tabular}

a, Mean \pm S.E.; $* \mathrm{P}<0.05$ vs Normal controls; ** $\mathrm{P}<0.01$ vs Normal controls by paired $t$ test.

Table 1. The pituitary and ovarian weights of normal, TP100A and TP1000A rats at different ages.

\begin{tabular}{clcccc}
\hline $\begin{array}{c}\text { Age } \\
\text { (weeks) }\end{array}$ & Groups & $\begin{array}{c}\text { No. of } \\
\text { rats }\end{array}$ & $\begin{array}{c}\text { Body wt. } \\
(\mathrm{g})\end{array}$ & $\begin{array}{c}\text { Pituitary } \\
(\mathrm{mg} / 100 \mathrm{~g} \text { Body }\end{array}$ \\
\hline 4 & Normal & 7 & $56.3 \pm 3.0^{\mathrm{a}}$ & $4.38 \pm 0.04$ & $31.5 \pm 3.6$ \\
& TP1000A & 12 & $57.2 \pm 2.0$ & $3.84 \pm 0.23$ & $26.0 \pm 1.1^{*}$ \\
7 & Normal & 8 & $164.8 \pm 8.1$ & $4.58 \pm 0.25$ & $38.1 \pm 4.0$ \\
& TP100A & 8 & $166.5 \pm 3.0$ & $4.95 \pm 0.24$ & $22.8 \pm 2.2^{* *}$ \\
& TP1000A & 9 & $160.5 \pm 5.4$ & $4.95 \pm 1.30$ & $16.3 \pm 1.0^{* *}$ \\
12 & Normal & 8 & $228.9 \pm 3.5$ & $4.51 \pm 0.09$ & $41.7 \pm 1.4$ \\
& TP100A & 8 & $265.4 \pm 9.5$ & $5.33 \pm 0.25^{* *}$ & $17.7 \pm 0.7^{* *}$ \\
& TP1000A & 11 & $243.6 \pm 5.0$ & $5.02 \pm 0.05^{* *}$ & $16.9 \pm 0.5^{* *}$ \\
\hline
\end{tabular}

a, Mean \pm S.E.; $* \mathrm{P}<0.05$ vs Normal controls; $* * \mathrm{P}<0.01$ vs Normal controls by paired $t$-test. 
controls (Table 1). The weights of the anterior pituitary in 12-week-old TP100A and TP1000A rats were significantly heavier than those in normal rats.

The relative ovarian weight in TP1000A rats showed a decrease already at 4 weeks of age. The vaginal smears in these animals showed persistent estrus since opening of the vaginal orifice. Ovarian weight of

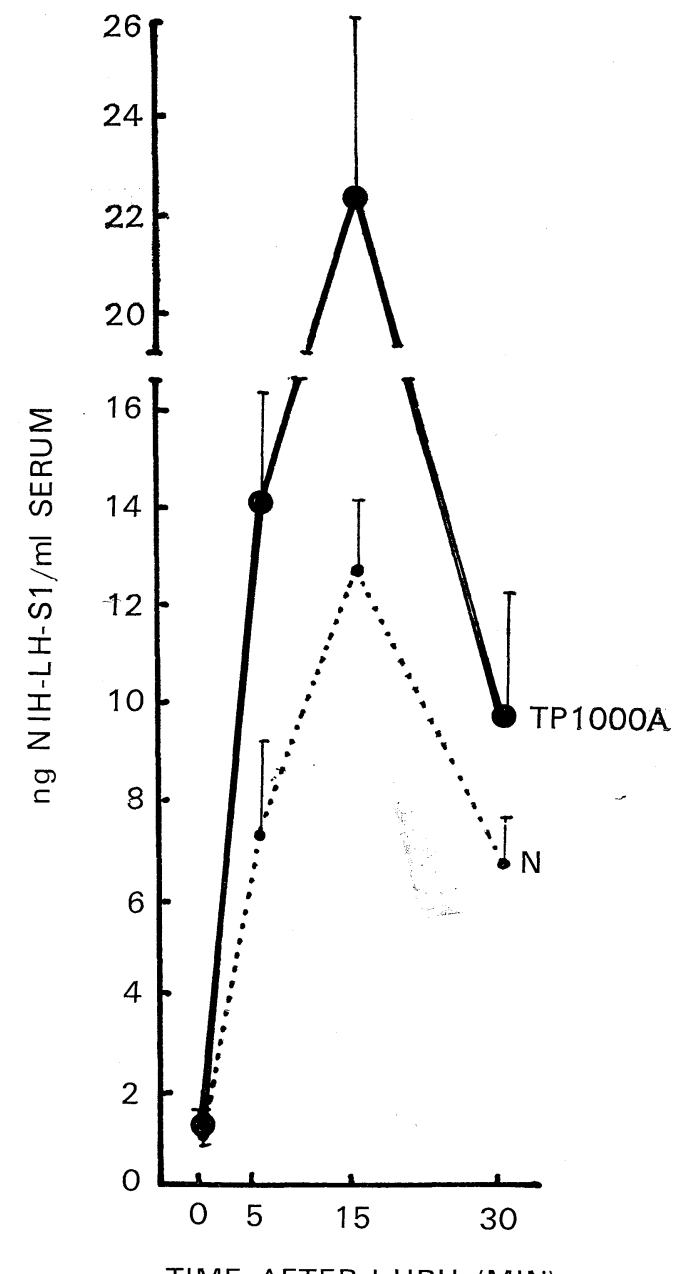

Fig. 1. Time course of the LH response to the iv injection of $5 \mu \mathrm{g} / \mathrm{kg}$ synthetic LHRH in 4 weeks old normal and TP1000A rats. $\mathrm{N}$, normal rats; TP1000A, androgenized with $1000 \mu \mathrm{g}$ testosterone propionate. Each point represents the mean \pm standard error of the mean derived from 4-5 rats.
TP100A rats showing persistent estrus was smaller than that of controls and the difference was more striking in adults (Table 1).

\section{LH Response}

The LH concentration per unit weight of the anterior pituitary was the highest in animals of 4 weeks of age among the age

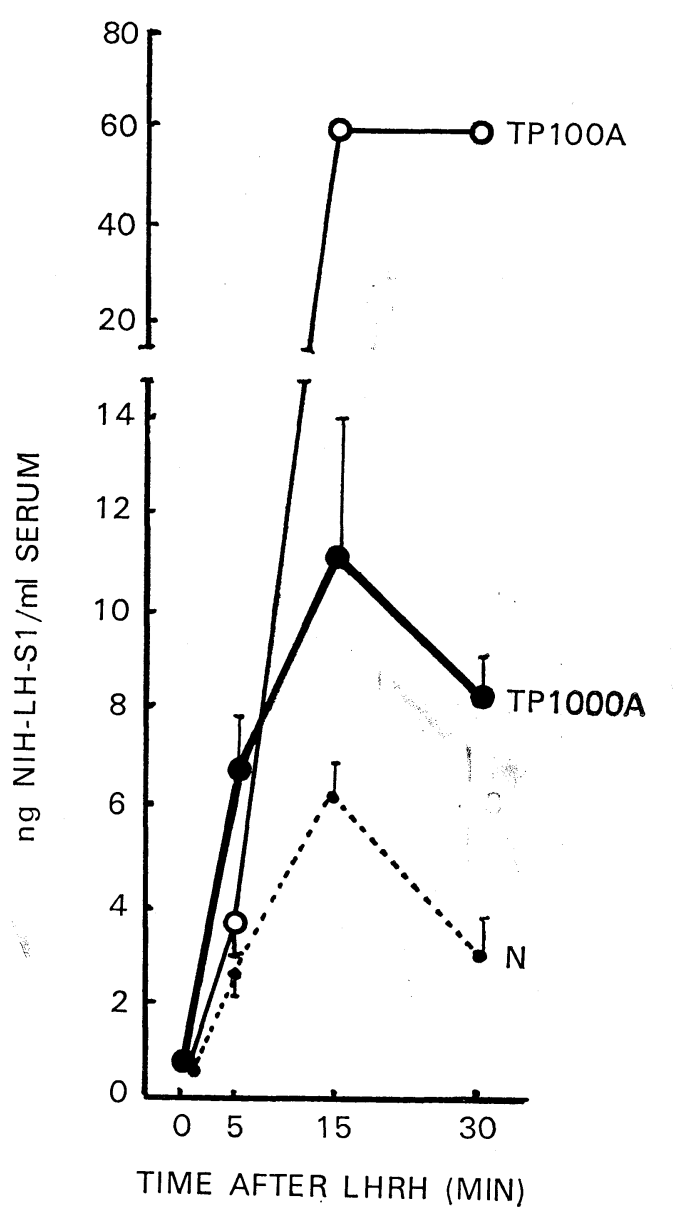

Fig. 2. Time course of the LH response to the iv injection of $5 \mu \mathrm{g} / \mathrm{kg}$ synthetic LHRH in 7 weeks old normal, TP100A and TP1000A rats. N, normal; TP100A, androgenized with $100 \mu \mathrm{g}$ testosterone propionate; TP1000A, androgenized with $1000 \mu \mathrm{g}$ testosterone propionate. Each point represents the mean \pm standard error of the mean derived from 4 rats. 
groups studied in normal and TP1000A groups (Table 2). The $\mathrm{LH}$ concentration in the anterior pituitary of the TP1000A rats was the lowest, though the differences were not always significant. A significant decrease in the LH concentration was shown in 12-week-old TP100A and TP1000A rats.

LHRH injection induced areater increase in the serum $\mathrm{LH}$ concentration in 4-week-old and 7-week-old androgenized rats than in normal controls (Figs. 1 and 2). A maximal response to LHRH was shown $15 \mathrm{~min}$ after the injection in both normal and androgenized groups. In 7week-old TP100A rats, the LH concentration increased up to $60 \mathrm{ng} / \mathrm{ml}$ serum $15 \mathrm{~min}$ after the injection of $5 \mu \mathrm{g} / \mathrm{kg}$ LHRH and this level was retained when examined at 30 min (Fig. 2). In 12-week-old TP100A and TP1000A rats, however, $\mathrm{LH}$ reiease by LHRH injection was significantly less than that in 12-week-old normal controls

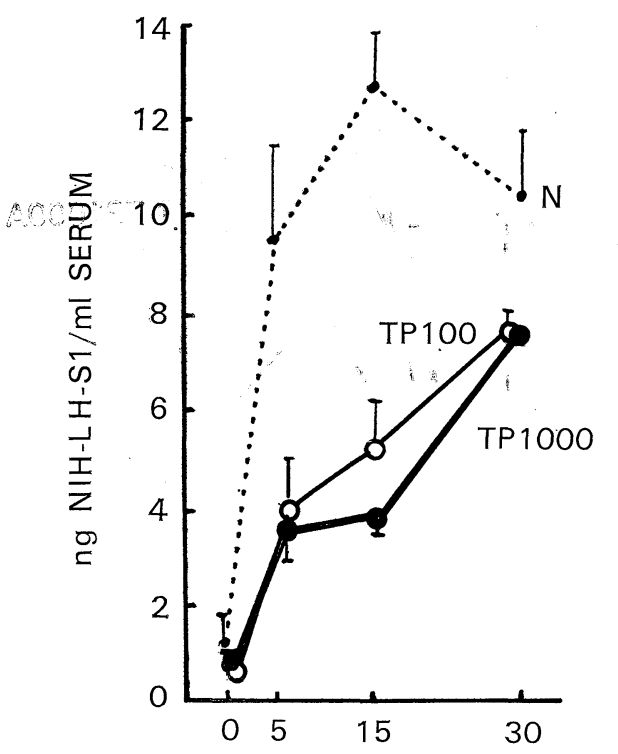

TIME AFTER LHRH (MIN)

Fig. 3. Time course of the LH response to the iv injection of $5 \mu \mathrm{g} / \mathrm{kg}$ synthetic LHRH in 12-weekold normal, TP100A and TP1000A rats. Each point represents the mean \pm standard error of the mean derived from 4-5 rats.
(Fig. 3). The LH release in these rats continued to increase up to $30 \mathrm{~min}$ after the injection, although the concentration was still lower than that in the controls.

Administration of an analog of LHRH, TAP127 which had been reported to possess a greater potency to stimulate the $\mathrm{LH}$ release (Fujino, et al., 1974) induced a greater increase in the serum LH concentration in both normal and androgenized

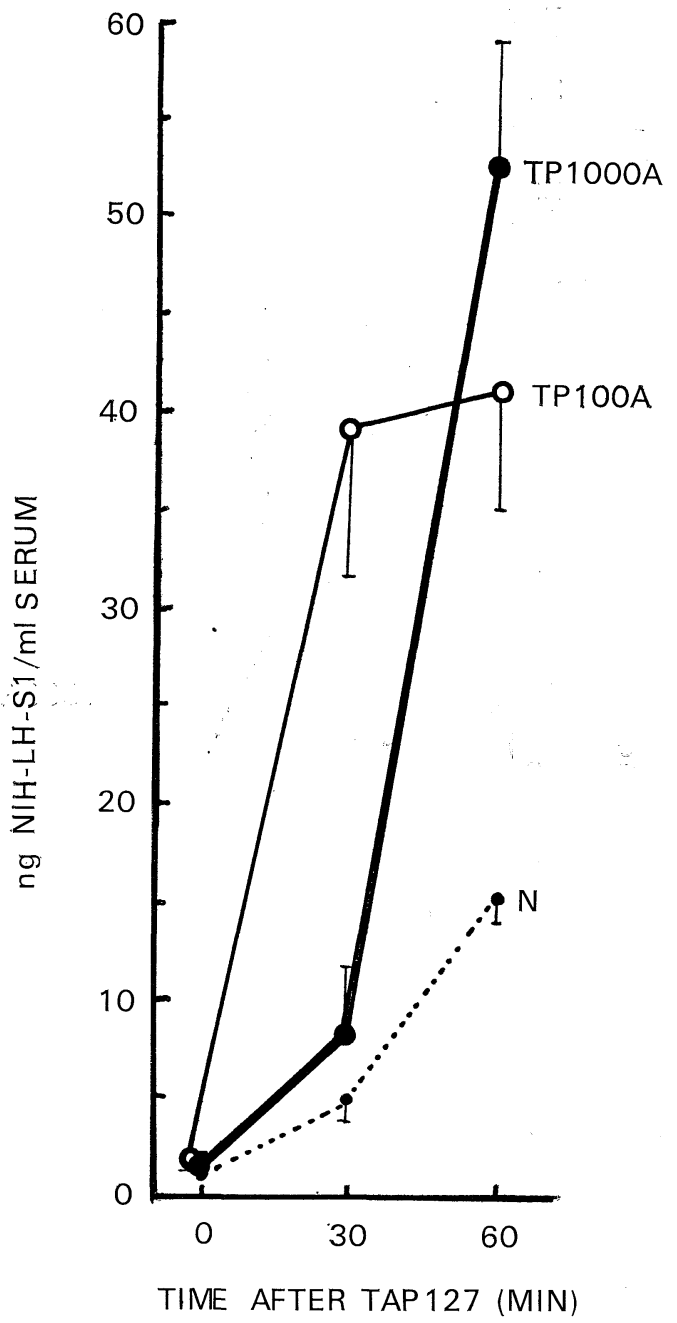

Fig. 4. Time course of the $\mathrm{LH}$ response to the iv injection of $0.5 \mu \mathrm{g} / \mathrm{kg}$ TAP127 in 7-week-old normal, TP100A and TP1000A rats. Each point represents the mean \pm standard error of the mean derived from 5-6 rats. 
rats at 7 and 12 weeks of age (Figs. 4 and 5). $\mathrm{LH}$ release by TAP 127 was continued to increase up to $60 \mathrm{~min}$ after the injection. The difference in the $\mathrm{LH}$ response between normal and androgenized groups of 12week-old rats was lesser than that shown following the injection of LHRH. The order of magnitude in $\mathrm{LH}$ release obtained after administration of $0.5 \mu \mathrm{g} / \mathrm{kg}$ TAP127 was 7-week-old TP100A $>7$-week-old TP$1000 \mathrm{~A}>12$-week-old normal $>12$-week-old TP100A $>12$-week-old TP1000A $>7$-weekold normal rats.

\section{Discussion}

The significance of estradiol in enhancing pituitary sensitivity to exogenous LHRH has been demonstrated (Vichez-

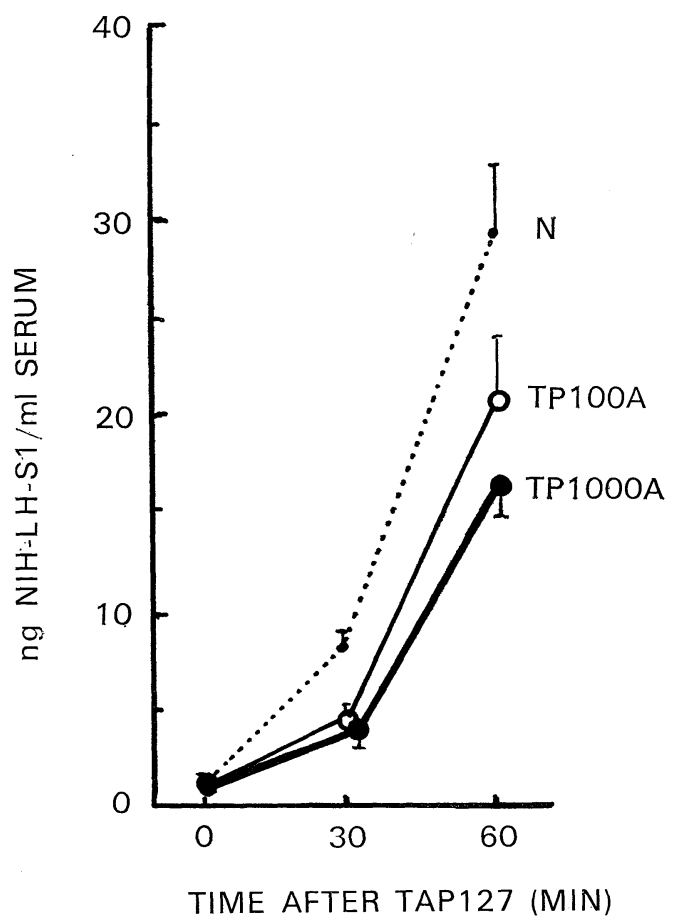

Fig. 5. Time course of the $\mathrm{LH}$ response to the iv injection of $0.5 \mu \mathrm{g} / \mathrm{kg}$ TAP127 in 12-week-old normal, TP100A and TP1000A rats. Each point represents the mean \pm standard error of the mean derived from 3-4 rats.
Martinez et al., 1974; Wilkinson et al., 1976). In rats with regular 4-day cycles, pituitary sensitivity to synthetic LHRH has been shown to increase between the early afternoon of diestrus and proestrus (Aiyer et al., 1974). In immature female rats, the serum $\mathrm{LH}$ and estradiol levels have been reported to be coincidentally high in animals between days 9 and 21 as compared with those in 25-day-old or adult female rats, suggesting a positive action of estradiol in LH release during a certain period even in prepubertal animals (Döhler and Wuttke, 1975). On the other hand, Debéljuk et al. (1972) have examined the age difference in $\mathrm{LH}$ response to exogenous LHRH in normal female rats and obtained the maximal response in rats at 15 and 25 days of age. In normal female rats in the present experiment, the $\mathrm{LH}$ release by synthetic LHRH in 4-week-old rats was the highest in the three age groups examined. And the $\mathrm{LH}$ response in 7-week-old rats on the day of estrus was lower than that in 12-week-old rats on the day of estrus. In androgenized rats, however, the LH release by LHRH in 4-week-old rats was about twice as high as that seen in normal controls. Moreover, the much larger response in LH release in 7-week-ol drats was observed; the response in TP100A rats was greater than that in TP $1000 \mathrm{~A}$ rats. In the present experiment, $70 \%$ of the TP100A rats showed persistent estrus at 7 weeks of age and the rats showing cornified vaginal smears at least for 7 days were tested for LH response. Their ovaries consisted of small cystic follicles resembling the ovaries of TP1000A rats, although the ovarian weights in TP100A rats were slightly heavier than those in TP1000A rats. In contrast to the results obtained in the young androgenized rats, $\mathrm{LH}$ release by $\mathrm{LHRH}$ in both TP100A and TP1000A adult rats was significantly lower than that in normal adult rats in spite of the sufficient amount of LH present in the pituitary in these 
animals. The ovaries of neonatally androgenized rats have been reported to produce larger amounts of estradiol, particularly during the immature period (Chen and Johnson, 1973): The values between days 10 and 20 were 5 to 6 times higher than those at day 25 and the lowest value was found on day 30. At older ages, the estradiol concentrations were similar to those in normal rats on the morning of proestrus. In normal rats, the relatively higher level of estradiol at days 10 and 15 decreased already at day 20 toward the level of adult animals. In view of the results obtained by us and other investigators as mentioned above, the remarkable age difference in $\mathrm{LH}$ response to LHRH in androgenized rats, particularly in the TP100A rats, cannot be simply explained by the different estrogen level in the serum. Not only estrogen but some other factors would play a role in enhancing responsiveness to LHRH in young androgenized rats and in suppressing the responsiveness in adult androgenized rats.

Bagdanove and Gay (1964) proposed that the accumulation of a readily releasable pool of hormone may be reflected in the pituitary responsiveness to LHRH. But there was no significant difference in the LH concentration in the anterior pituitary between normal and TP100A rats at 7 weeks of age, though the serum LH level in 7-week-old TP100A rats was approximately ten-fold higher than that in 7-weekold normal rats at $15 \mathrm{~min}$ following the injection of LHRH and a prolonged $\mathrm{LH}$ release was evident until $30 \mathrm{~min}$. These findings clearly show that the availability of pituitary LH is not necessarily the only determining the magnitude of the response to $\mathrm{LHRH}$ in $\mathrm{LH}$ release. A prolonged release of LH in 7-week-old TP100A rats may suggest that the ability of gonadotrophs to synthesize $\mathrm{LH}$ is elevated.

TP100A and TP1000A rats as well as normal female rats responded to TAP127, a potent stimulator of $\mathrm{LH}$ release, to a greater extent than the response by LHRH administration. The increased sensitivity at 7 weeks of age and the decreased sensitivity at 12 weeks of age were also shown when compared with that in normal controls. Furthermore, the enhanced response to gonadotropin-releasing hormone in 7-weekold TP100A and TP1000A rats was confirmed by the administration of TAP127.

Anovulation in androgenized rats has generally been considered to be due to the lack of cyclic discharge of LH (Kurcz et al., 1969; Flerkó et al., 1969). The present results clearly indicate that the pituitary in androgenized rats responds to LHRH to a much larger extent during the premature period and its responsiveness declines during the course of maturation. Furthermore, androgenization with a lower dose of testosterone propionate conspicuously manifested changes in the sensitivity of the pituitary to gonadotropin-releasing hormone. Factors associated with the effects of testosterone propionate in the hypothalamus in producing anovulatory state in rats may play a key role in manifesting the phenomena observed in the present experiments.

\section{Acknowledgements}

We gre grateful to Dr. A. F. Parlow, Harbor General Hospital, Torrance, California and to the National Institute of Arthritis and Metabolic Diseases, The Rat Pituitary Hormone Program, for the generous supply of LH radioimmunoassay kit. We are also grateful to Dr. M. Fujino, Takeda Pharmaceutical Co. for the gift of TAP127 and to Mochida Pharmaceutical Co. for LHRH.

\section{References}

Aiyer, M. S. and G. Fink (1974). J. Endocr. 62, 553. Bagdanove, E. M. and V. L. Gay (1964). Endocrinology 81, 930.

Barraclough, C. A. (1966). Recent Progr. Hormone Res. 22, 503.

Borvendég, J., H. Hermann and S. Bajusz (1972). J. Endocr. 55, 207. 
Chen, H. C. and D. C. Johnson (1973/74). Neuroendocrinology 13, 357.

Cortes, V., J. A. McCracken, C. W. Lloyed and J. Weisz (1971). Endocrinology 89, 878.

Debéljuk, L., A. Arimura and A. V. Schally (1972). ibid. 90, 1499.

Döhler, K. D. and W. Wuttke (1975). ibid. 97, 898.

Flerkó, B., B. Mess and A. Illsi-Donhoffer (1969). Neuroendocrinology 4, 164.

Fujii, T., J. Kato and K. Wakabayashi (1974). 22nd Ann. Meet. East. Branch Jap. Endocr. Soc. Abstr. 102. (In Japanese)

Fujino, M., I. Yamasaki, S. Kobayashi, T. Fukuda,
S. Shinagawa and R. Nakayama (1974). Biochem. Biophys. Res. Comm. 57, 1248.

Kurcz, M., K. Maderspach and G. Horn (1969). Acta Biol. Acad. Sci. Hung. 20, 303.

Vichez-Martinez, J. A., A. Arimura, L. Debéljuk and A. V. Schally (1974). Endocrinology 94, 1300.

Wakabayashi, K., P. Asai and H. Matsu-ura (1975). Gunma Symp. Endocrinol. 12, 65.

Wilkinson, M., D. de Ziegler and K. B. Ruf (1976). J. Endocr. 70, 155.

Ying, S.-Y. (1973). Proc. Soc. Exp. Biol. Med. 144, 822. 